\title{
Medicinal plants and their contribution in socio-economic condition of the household in Haluaghat upazila, Mymensingh
}

\author{
Mohammad Rizwanul Bari ${ }^{1}$, Md. Aslam Ali ${ }^{2}$ Md. Giashuddin Miah ${ }^{3}$ and Md. Rishad \\ Abdullah ${ }^{1}$ and Md. Jashim Uddin ${ }^{4}$
}

\author{
${ }^{1}$ Dept. of Agrofestry, Bangladesh Agricultural University, Mymensingh \\ ${ }^{2}$ Dept. of Environmental Sciences, Bangladesh Agricultural University, Mymensingh \\ ${ }^{3}$ Dept. of Agroforestry, Bangabandhu Sheikh Mujibur Rahman Agricultural University, Gazipur \\ ${ }^{4}$ Upazila Agriculture Officer, Upazila Agriculture Officer, Ramganj, Laksmipur, Bangladesh
}

$\triangle$ For any information: ask.author@journalbinet.com

Article Received: 07.08.17; Revised: 26.09.17; Published online: 25 November 2017.

\begin{abstract}
The study was conducted at Haluaghat upazila of Mymensingh district to identify the existing medicinal plant species, their uses and their contribution to the socio-economic development of the household. Data were collected from the selected respondents by using structured questionnaires during September to October 2004. About 90 useful medicinal species were identified; among them 30 were tree species, 29 shrubs and 31 herbs. The prevalent tree species with medicinal value in the study area were Amloki (3.20), Neem (3.13), Nishinda (2.66), Kharajora (2.56), Sheora (2.01), Arjun (1.92), Chalta (1.87) etc. Most prevalent medicinal shrub species were Cassava (4.56) followed by Bashak (2.09), Akanda (1.98), Papaya (1.67), Dhalim (1.12) etc. and most prevalent medicinal hurb species were Vat (23.80), Bonhalud (13.67), Patharkuchi (6.41), Apung (6.30), Lajjabati (4.81), Pumonava (4.74) etc. Economically potential species were Arjun, Amloki, Horitaki, Ulotkombal, Ghritakanchan etc. The relationship between socio-economic condition with selected characteristics such as age and homestead area was found insignificant; while the rest characteristics like education level, family size, farm size, overall annual income, income from medicinal plants, knowledge on medicinal plants, preference towards medicinal plants of the respondents were found statistically significant which motivated them to raise the medicinal plant species in their homestead area. From the socio-economic point of view, medicinal plants provided a critical source of income for many rural communities, especially landless poor and marginalized farmers. The plant species having high commercial value may be utilized as a source of income for the rural farmers. It was noticed that the respondents reduced health care cost by using this indigenous trees, shrubs and herbs. Moreover, the people who took kavirazi as a profession and contributed in rural health care were well known and given higher respect from the society. Unfortunately, medicinal plants are increasingly threatened by various environmental, socioeconomic and institutional problems. Most of the respondents opined that their problems were mainly related to lack of land, time, inputs, proper knowledge, economic support and unwillingness to cultivate and conserve medicinal plants. However, proper training with adequate supply of desired medicinal plant species are required and credit facilities would be helpful for large scale cultivation of medicinal plants.
\end{abstract}

Key Words: Medicinal plant species, Uses and Socio-economic characteristics 
Cite Article: Bari, M. R., Ali, M. A., Miah, M. G., Abdullah, M. R. and Uddin, M. J. (2017). Medicinal plants and their contribution in socio-economic condition of the household in Haluaghat upazila, Mymensingh. International Journal of Business, Management and Social Research, 04(01), 215-228. Crossref: https://doi.org/10.18801/ijbmsr.040117.25

Article distributed under terms of a Creative Common Attribution 4.0 International License.

\section{Introduction}

Most of the identified plant species were virtually left on growing in the natural habitats in forests, villages, rural households; which contributed directly or indirectly in the rural economy of Bangladesh through providing forest products, fruits, fodder and fuel. In addition, it also supplies raw materials for medicinal purposes (Bashu and Manna, 1997). Medicinal plants have been used in Bangladesh in Ayurvedic and folk medicine since ancient times. Rashid et al. (1987) has conducted research work into the nature and functional dynamics of crude drug market in Bangladesh. They observed that different Ayurvedic, Unani and other pharmaceutical industries of the country commonly used some 142 different crude drugs. According to the World Health Organization (WHO), medicinal plants form the basis of traditional and indigenous health care needs used by the majority of the world's population. Modern Pharmacopoeia still contains at least 25\% drugs derived from plants, which are synthetic analogues built on prototype compounds isolated from plants (Silva, 1997).

From the socio-economic point of view, medicine is an important commodity in our life, often considered as life saving item. About $90 \%$ of the total medicines come from plant kingdom (Rahman, 2003). From the ancient era, plants have been used for treatment of several diseases. According to experts, the herbal plants belonging to 60 families out of 206 are used for medicinal purposes in Bangladesh (Roy, 2001). In many parts of the country particularly in adjoining forest and hilly area like Haluaghat are the wild collection of medicinal species used mainly by the poor in their livelihood activity and often a major source of cash income for these groups. Most of the people of rural areas go to the kaviraj, even to Homeopathic or Allopathic doctors. The kaviraj who has vast knowledge on the medicinal plants and their uses against different diseases give treatment to the poor villagers with indigenous medicinal plants. Therefore, the scientific cultivation and sustainable uses of medicinal plants are very important to the socio-economic development of the rural people. However, it is a matter of great regret that a very few medicinal plants have been cultivated scientifically as well as commercially for purpose of medicine extraction. Due to the destruction of forests, over grazing of remote and marginal lands, expansion of industries and urbanization as well as excessive harvesting of wild rare and endangered plant species, biological diversity of medicinal plants has been reduced day by day (Xiao, 1991). Moreover, insufficient supports from the government and public policies, lack of appropriate management and institutional strategies have been drastically eroded those valuable resources.

Protection and conservation of medicinal plant resources were not considered as a major concern until 1984 (Hannah and Bowles, 1995). In the past, many countries have failed to adequately enforce on genetic resources of medicinal plants due to lack of awareness of the potential value of the species (Walden, 1995). From the conservation point of view, many of our traditional medicinal plants are now extinct. Some are endangered and some are totally threatened. For these reasons, the study was conducted to identify the potential medicinal species, uses and their contribution on socio-economic conditions of the people. The results may help the social workers, program planners and policy makers to design their development strategy for over all socio-economic development of the poor rural people through cultivation and conservation of potential medicinal plant species in the study area.

\section{Materials and Methods}

Seven unions Amtail, Bhubankura, Gazirbhita, Haluaghat, Jugli, Narail and Swadeshi were selected purposively from 12 unions Haluaghat upazila of Mymensingh district. A total of 20 villages were taken from these seven unions for survey by the help of Upazila Agriculture Extension Office of DAE, 
World Vision and local people of Haluaghat. Seventy-five respondents were interviewed in the selected area to collect data on medicinal plants, their uses and socio-economic importance. Other important related factors were also collected from them by using structured questionnaire. Interview schedule was carefully designed keeping the objectives of the study to collect data. It contained both opened and closed form of questions. Initially the questionnaire was designed in Bengali for easy recording with the respondents. The interview schedule was administered by the researcher personally to the respondents Collected data was verified through surveying the homestead and discussing with the households. Data were collected during September to October 2004. Identification of the existing medicinal trees, shrubs and herbs species was done in the field with the help of rural aged people, local traditional doctors (kabiraj) while the others that could not be readily identified were brought to the herbarium of department of agroforstry, Bangladesh Agricultural University. The scientific names were obtained by consulting the literature (BARC, 1972-1992; Chopra et al., 1992; Chevallier, 1996; Das and Alam, 2001). Asking respondents views on different issues and problems regarding medicinal plants were ranked. The questions were framed with several options and therefore, multiple responses were noted from each respondent. Scores for each option by each respondent were added together to obtain a total score/ weight for that option and relatively ranked according to total score/weight.

Processing and analysis of data: After collection, the collected data were coded for processing and analysis. Local units were converted into standard units. The researcher transferred data to a Master Sheet to facilitate tabulation. Necessary tabulation were also computed by SPSS programme. Some statistical and mathematical analysis was also done for ranking and other purposes. Survey findings were compared on the basis of farm categories. This data were classified and presented in tabular form to realize the actual status of medicinal plants, their uses and contribution to socio-economic development of the rural people. Statistical record in the terms of number, percentage, range, mean and correlation were used in describing the variables of the research for clarity of understanding, tables, graphs and photographs were also used for presenting the data. Responses of the complete interview schedule were numerically coded and analyzed. Pearson's Product Moments correlation was used to find out the relationship between independent and dependent variables. 5 percent $(0.05)$ and 1 percent (0.01), level of probability was used as the basis for rejection of any null hypothesis whenever necessary throughout the analysis.

Relative prevalence of species: Prevalence of medicinal plants means general widespread of medicinal plants in a particular area. To indicate the importance and species richness of different plants in homestead area, a relative prevalence of species in per unit area was determined by the following formula (Bashar, 1999).

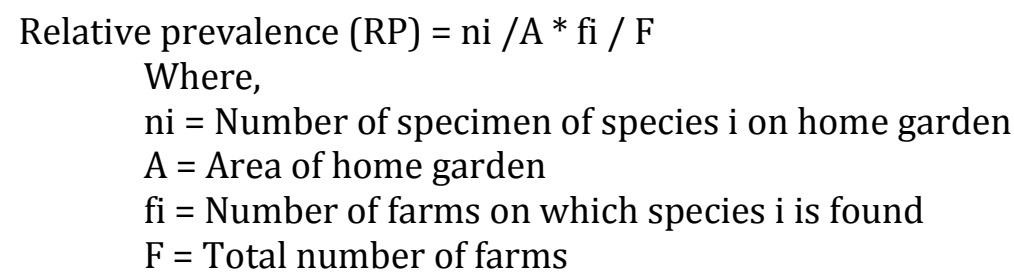

Socio-economic condition (dependent variable): Socio-economic conditions of the respondents were defined as the improvement of social as well as economic status towards positive direction. The respondents were asked to give their opinion regarding the socio-economic development in addition to their livelihood due to the direct or indirect contribution of medicinal plants. It was measured on the basis of respondents' opinion obtained from the 12 selected items containing information on the improvement of socio-economic conditions of their livelihood as shown in the item number $\mathrm{G}$ of the interview schedule. Each respondent indicated the extent of development answering any of the four responses, viz. very much change, substantial change, little change and no change. The weights were assigned to each of the scale as 3, 2, 1 and 0 for "Very much change", "Substantial change", "Little change" and "No change", respectively. Range of socio-economic scores was from 0 to 36, where 0 indicated no change in socio-economic condition and 36 indicated very high change.

Respondents Opinion Index (ROI) was computed from the opinions provided by the respondents in regards to contribution of medicinal plants in the development of their socio-economic-condition. The 
ROI calculated by multiplying the frequency counts of each of the scale of individual consequence with its corresponding scores as 3, 2, 1 and 0 for "Very much change", "Substantial change", "Little change" and "No change", respectively. Finally by adding all the frequency counts of each cell of the scale, the value of ROI was calculated.

\section{Results and Discussion}

\section{Relative prevalence of medicinal plant species in the study area}

About 90 useful medicinal plants (trees, shrubs and herbs) were identified in the studied homestead of the respondents. Prevalence of medicinal plant species means general widespread of that type of plant species in a particular area. It is always measured as relative prevalence. The highest prevalent tree species with medicinal value in the study area were Amloki (3.20), Neem (3.13), Nishinda (2.66), Kharajora (2.56), Sheora (2.01), Arjun (1.92), Chalta (1.87) etc. Most prevalent medicinal shrub species were Cassava (4.56) followed by Bashak (2.09), Akanda (1.98), Papaya (1.67), Dhalim (1.12) etc. and most prevalent medicinal herb species were Vat (23.80), Bonhalud (13.67), Patharkuchi (6.41), Apung (6.30), Lajjabati (4.81), Purnonava (4.74) etc. was found in almost all farm categories due to ecological and physiographic factors. There were minor differences in relative prevalence of less common species. The relative prevalence of medicinal plants is presented in Table 01 (Tree species) and Table 02 (Shrub and herb species).

Table 01. Relative prevalence of medicinal tree species identified in the study area

\begin{tabular}{l|llll}
\hline Sl No. & Local Name & Scientific Name & Family & $\begin{array}{l}\text { Relative prevalence } \\
\text { (per unit area) }\end{array}$ \\
\hline 1. & Amloki & Phyllanthus emblica & Euphorbiaceae & 3.20 \\
2. & Neem & Azadiracta indica & Meliaceae & 3.13 \\
3. & Nishinda & Vitex negundo & Verbenaceae & 2.66 \\
4. & Kharajora & Litsea monopetala & Lauraceae & 2.56 \\
5. & Sheora & Streblus asper & Moraceae & 2.01 \\
6. & Arjun & Terminalia arjuna & Combretaceae & 1.92 \\
7. & Chalta & Dellenia indica & Delleniaceae & 1.87 \\
8. & Kalojam & Syzygium cummini & Myrtaceae & 1.66 \\
9. & Peyara & Psidium guajava & Myrtaceae & 1.46 \\
10. & Khejur & Phoenix sylvestris & Palmae & 1.25 \\
11. & Jigar & Lagerstroemia thoxelly & Lythraceae & 0.66 \\
12. & Tal & Borassus flabellifer & Palmae & 0.66 \\
13. & Ulot Kambal & Abroma augusta & Sterculiaceae & 0.62 \\
14. & Mandar & Ervthrinu variegata & Leguminosae & 0.50 \\
15. & Bael & Aegle marmelos & Rutaceae & 0.47 \\
16. & Sazna & Moringa oleifera & Moringaceae & 0.34 \\
17. & Shimul & Bombax ceiba & Bombacaceae & 0.22 \\
18. & Hijal & Barringtonia acutangula & Euphorbiaceae & 0.166 \\
19. & Horitoki & Terminalia chebula & Combretaceae & 0.167 \\
20. & Sonalu & Cassia fistula & Liguminosae & 0.146 \\
21. & Bon nalia & Cielonium multillorum & Euphorbiaceae & 0.111 \\
22. & Kanaidinga & Oroxylum indicum & Bigoniaceae & 0.033 \\
23. & Kamranga & Averrhaa carambola & Oxalidaceae & 0.019 \\
24. & Chatim & Alstonia scholaris & Apocynaceae & 0.016 \\
25. & Ashoke & Saraca ashoka & Caesalpiniaceae & 0.016 \\
\hline
\end{tabular}


Table 02. Relative prevalence of medicinal species (shrubs \& herbs) identified in the study area

\begin{tabular}{|c|c|c|c|c|}
\hline Sl No. & Local Name & Scientific Name & Family & $\begin{array}{l}\text { Relative prevalence } \\
\text { (per unit area) }\end{array}$ \\
\hline \multicolumn{5}{|c|}{ Shrubs } \\
\hline 1. & Cassava & Manihot esculenta & Euphorbiaceae & 4.56 \\
\hline 2. & Basak & Adhatoda Zelanica & Acanthaceae & 2.09 \\
\hline 3. & Akanda & Calotropis gigantica & Asclepiadaceae & 1.98 \\
\hline 4. & Papaya & Carica papaya & Caricaceae & 1.67 \\
\hline 5. & Dalim & Punica granatum & Punicaceae & 1.12 \\
\hline 6. & Mehedi & Lawsonia inermis & Leguminosae & 0.95 \\
\hline 7. & Lemon & Citrus aurantifolia & Rutaceae & 0.36 \\
\hline 8. & Chirata & Swertia chirata & Gentianaceae & 0.33 \\
\hline 9. & Daruharidra & Morinda angustifolia & Berbiridaceae & 0.325 \\
\hline 10. & Datura & Datura netel & Solanaceae & 0.185 \\
\hline 11. & Sharpogandha & Rouwlfia serpentina & Apocinaceae & 0.133 \\
\hline 12. & Nayantara & Vinka rosea & Apocynaceae & 0.123 \\
\hline 13. & Isharmul & Aristolochia indica & Solanaceae & 0.070 \\
\hline \multicolumn{5}{|c|}{ Herbs } \\
\hline 14. & Vat & Clerodendron injortunatum & Verbinaceae & 23.80 \\
\hline 15. & Banhalud & Curcuma aromatica & Zingiberaceae & 13.67 \\
\hline 16. & Patharkuchi & Bryophyllum calycinum & Crassulaceae & 6.41 \\
\hline 17. & Apang & Achyranthes aspera & Amaranthaceae & 6.30 \\
\hline 18. & Lazzabati & Mimosa pudica & Mimosae & 4.81 \\
\hline 19. & Purna nava & Boerhaovia repens & Nyctaginaceae & 4.74 \\
\hline 20. & Tulsi & Ocimum sanctum & Labiatae & 3.18 \\
\hline 21. & Banada & Zingiber perpureum & Zingiberaceae & 3.10 \\
\hline 22. & Thankuni & Centella asiatica & Myrtaceae & 2.33 \\
\hline 23. & Marigold & Tagetes ereeta & Compositae & 2.50 \\
\hline 24. & Keoa Jungia & Lachrima jobi & Grameneae & 2.20 \\
\hline 25. & Sheal motra & Vernonia patula & Composite & 2.01 \\
\hline 26. & Keoa danga & Costus spesiosus & Unknown & 2.02 \\
\hline 27. & Amada & Curcuma amada & Zingiberaceae & 2.00 \\
\hline 28. & Ara root & Curcuma angustifolia & Zingiberaceae & 1.6 \\
\hline 29. & Banrasun & Cyanotis cristata & Commenlinaceae & 1.68 \\
\hline 30. & Biskatali & Polygonum orientale & Poligonaceae & 1.52 \\
\hline 31. & Ghritokumari & Aloe vera & Liliaceae & 1.52 \\
\hline 32. & ArhorWral & Cajanas cajan & Leguminosae & 1.33 \\
\hline 33. & Gondha vadulia & Paederia foetida & Rubiaceae & 1.33 \\
\hline 34. & Pepul & Piper longum & Piperaceae & 1.16 \\
\hline 35. & Pudina & Mentha arvensis & Labiatae & 0.873 \\
\hline 36. & Bish kachu & Steudnera virosa & Araceae & 0.83 \\
\hline
\end{tabular}

\section{Selected characteristics of the respondents}

Age: Age of the respondents ranged from 25 to 88 years with an average of 50.36 and standard deviation of 13.53. The respondents were classified into three categories on the basis of their age namely young, middle and old aged. The categories were presented in the Table 03. Data contained in Table 03 showed that the highest proportion of the respondents $(58.66 \%)$ belonged to middle aged category. The old and young aged categories represented $25.33 \%$ and $16 \%$ of the total respondents, respectively. 
Table 03. Salient features of selected characteristics of the respondents

\begin{tabular}{|c|c|c|c|c|c|c|c|c|}
\hline \multirow{2}{*}{ 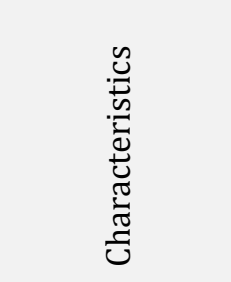 } & \multirow[b]{2}{*}{ Categories } & \multicolumn{2}{|c|}{ Respondents } & \multirow[b]{2}{*}{ 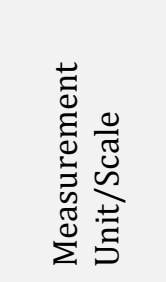 } & \multicolumn{2}{|l|}{ Range } & \multirow[b]{2}{*}{ Mean } & \multirow[b]{2}{*}{$\begin{array}{l}\text { Std. } \\
\text { Dev. }\end{array}$} \\
\hline & & No. & $\%$ & & Min. & Max & & \\
\hline \multirow{3}{*}{ Age } & Young aged (25-40 years) & 19 & 25.33 & \multirow{4}{*}{ Years } & \multirow{3}{*}{25} & \multirow{3}{*}{88} & \multirow{3}{*}{50.36} & \multirow{3}{*}{13.53} \\
\hline & Middle aged ( $41-60$ years) & 44 & 58.66 & & & & & \\
\hline & Old aged (above 60 years) & 12 & 16 & & & & & \\
\hline \multirow{5}{*}{$\begin{array}{l}\text { Education } \\
\text { level }\end{array}$} & Illiterate & 33 & 44 & & \multirow{5}{*}{0.0} & \multirow{5}{*}{14} & \multirow{5}{*}{3.88} & \multirow{5}{*}{4.25} \\
\hline & Primary level & 26 & 34.66 & \multirow{4}{*}{$\begin{array}{l}\text { Year of } \\
\text { schooling }\end{array}$} & & & & \\
\hline & Secondary level & 8 & 10.66 & & & & & \\
\hline & Higher secondary level & 5 & 6.68 & & & & & \\
\hline & $\begin{array}{l}\text { Above higher secondary } \\
\text { level }\end{array}$ & 3 & 4 & & & & & \\
\hline \multirow{3}{*}{ Family size } & Small (2-4 persons) & 11 & 14.66 & \multirow{4}{*}{$\begin{array}{l}\text { No. of } \\
\text { family } \\
\text { members }\end{array}$} & \multirow{3}{*}{3} & \multirow{3}{*}{15} & \multirow{3}{*}{6.69} & \multirow{3}{*}{2.25} \\
\hline & Medium (5-9 persons) & 57 & 76 & & & & & \\
\hline & Large (above 10 persons) & 7 & 9.33 & & & & & \\
\hline \multirow{5}{*}{ Farm size } & Landless (up to $0.2 \mathrm{ha}$ ) & 23 & 30.66 & & & & & \\
\hline & Marginal (0.21-0.6 ha) & 27 & 36 & \multirow{4}{*}{ Hectare } & & & & \\
\hline & Small (0.61-1.0 ha) & 16 & 21.33 & & 0.04 & 4.0 & 0.72 & 0.85 \\
\hline & Medium (1.01-2.0 ha) & 4 & 5.33 & & & & & \\
\hline & Large (above 2 ha) & 5 & 6.66 & & & & & \\
\hline & Landless (up to 0.05 ha) & 1 & 1.33 & & & & & \\
\hline & Marginal (0.06-0.10ha) & 29 & 38.66 & & & & & \\
\hline Homestead & Small (0.11-0.20 ha) & 26 & 34.66 & Hectare & 0.04 & 0.7 & 0.189 & 0.139 \\
\hline & Medium (0.21-0.50ha) & 17 & 22.66 & & & & & \\
\hline & Large (above $0.50 \mathrm{ha}$ ) & 2 & 2.66 & & & & & \\
\hline & Very low income (10-20) & 15 & 20 & & & & & \\
\hline Overall annual & Low income (21-50) & 26 & 34.66 & Thousand & 10 & 240 & 5865 & 4504 \\
\hline income & Medium income (51-120) & 27 & 36 & Taka & 10 & $\angle 40$ & 58.05 & 45.04 \\
\hline & Higher income (above 120) & 7 & 9.33 & & & & & \\
\hline Income from & No income $(0)$ & 22 & 29.33 & Thousand & & & & \\
\hline medicinal & Low income $(0.1-1.5)$ & 28 & 37.33 & $(' 000)$ & 0.0 & 7.0 & 1.3 & 1.37 \\
\hline plants & $\begin{array}{l}\text { Medium income }(1.6-4) \\
\text { High income (above } 4)\end{array}$ & $\begin{array}{l}22 \\
3\end{array}$ & $\begin{array}{l}29.33 \\
4\end{array}$ & Taka & & & & \\
\hline Knowledge on & Low (1-20) & 36 & 48 & & & & & \\
\hline medicinal & Medium (21-34) & 19 & 25.33 & Scoring & 10 & 98 & 26.40 & 19.30 \\
\hline plants & High (above 34) & 20 & 26.66 & & & & & \\
\hline Preference & Low (0-45) & 37 & 49.33 & & & & & \\
\hline towards & Medium (46-75) & 34 & 53.33 & Scoring & 10 & 190 & 5180 & 3478 \\
\hline $\begin{array}{l}\text { medicinal } \\
\text { plants }\end{array}$ & High (above 75) & 14 & 18.66 & & & & & \\
\hline
\end{tabular}

Education level: Education level of the respondents ranged from 0 to 14 years with an average of 3.88 and standard deviation of 4.25. Based on their education scores, respondents were classified into five categories. The categories were presented in the Table 03. Data contained in Table 03 showed that the majority of the respondents (44\%) were found to be illiterate. In primary level, secondary level and higher secondary level $36.44 \%, 10.66 \%$ and $6.66 \%$ were found, respectively. Among total respondents only $4 \%$ were educated above higher secondary level.

Family size: Family size of the respondents varied from 3 to 15 with an average of 6.69 and standard deviation of 2.25. Based on their family size scores, respondents were classified into three categories. The categories were presented in the Table 03 . Table 03 showed that most of the respondents (76\%) had medium size families compared to $14.66 \%$ of them having small families and $9.33 \%$ respondents had large families. 
Farm size: Farm size of the respondents ranged from 0.04 to 4 ha, the average being 0.72 ha with a standard deviation of 0.85 . The respondents were classified into five categories on the basis of their farm size. The categories were presented in the Table 03.

Data contained in Table 03 showed that $30.66 \%$ respondents were landless. The highest proportion of respondents (36\%) belonged to marginal farm category, $21.33 \%$ had small farm and $5.33 \%$ fell into medium category. Among them $6.66 \%$ respondent only owned large farms.

Homestead area: Homestead area of the respondents varied from 0.04 to 0.7 ha with an average of 0.189 ha and standard deviation of 0.139 . Based on their homestead area, respondents were classified into five categories. The categories were presented in the Table 03.

Data contained in Table 03 shows that highest proportion of the respondents $(38.66 \%)$ fell in to marginal farm category and the lowest proportion (1.33\%) belonged to landless category on the basis of their homestead area compared to $34.66 \%, 22.66 \%$ and $2.66 \%$ of small, medium and large homestead area, respectively.

Overall annual income: Annual income of the respondents varied from 10,000 to 240,000 taka per annum with an average of 58.65 thousand taka and standard deviation of 45.04 . On the basis of annual income scores, the respondents were classified into four categories as shown in Table 03. Data contained in Table 03 showed that $20 \%$ of the total respondents was found to be very low category, where $34.66 \%, 36.00 \%$ and $9.34 \%$ comprised the low, medium and high categories, respectively, regarding their overall annual income.

Income from medicinal plants: Annual income from medicinal plants of the respondents varied from no income to 7000 taka per annum with an average of 1.30 thousand taka and standard deviation of 1.37. On the basis of annual income from medicinal plants, the respondents were classified into four categories as shown in Table 03. Data contained in Table 03 showed that most of the respondents (37.33\%) fell into low-income category, whereas $29.33 \%$ respondents had no income from medicinal plants. Among them $29.33 \%$ had medium income and only $4 \%$ had high annual income.

Knowledge on medicinal plants: The computed knowledge scores of the respondents on medicinal plants ranged from 10 to 98 . The average was 26.40 with a standard deviation of 19.30 . Based on their knowledge scores, respondents were classified in three categories as shown in Table 03. Data contained in Table 03 showed that highest proportion of the respondents (48\%) had low knowledge on medicinal plants while $25.33 \%$ respondents had medium knowledge and $26.66 \%$ had high knowledge concerning medicinal plants.

Preference towards medicinal plants: Preference towards medicinal plants of the respondents was evaluated by the existing medicinal plant populations available in their households that ranged from 10 to 190 with an average of 51.80 and standard deviation of 34.78 . Based on their preference towards medicinal plants, respondents were classified into three categories as shown in Table 03. Data contained in Table 03 showed that most of the respondents (53.33\%) fell into medium category compared to $49.33 \%$ of them found in low category and $18.66 \%$ belonged to high category according to their preference towards medicinal plants.

Socio-economic condition (Dependent variable): The computed scores of the respondents' opinions on their socio-economic conditions in regards to contribution of medicinal plants ranged from 0 to 36. The average score was 14.72 with 7.61 standard deviation. Based on these scores, respondents were classified into three categories. Regarding their socio-economic conditions, most of the respondents (53.33\%) fell into the medium category, while $32 \%$ found in low category. Among the total respondents, $14.67 \%$ had high socio-economic condition in the study area. The information provided in Table 04 indicated that highest proportion $10.15 \%$ of the respondents opined "Increased family income" followed by "Increased knowledge on medicinal plants", "Reduced treatment cost", "Increased social status", "Increasing economic security" were ranked by $1^{\text {st }}, 2^{\text {nd }}, 3^{\text {rd }}, 4^{\text {th }}$ and $5^{\text {th }}$ respectively. The above mentioned consequences were the results of contribution of medicinal plants on socio-economic conditions of the respondents. 
Table 04. Respondents' opinion index (ROI) for socio-economic development regarding the contribution of medicinal plants

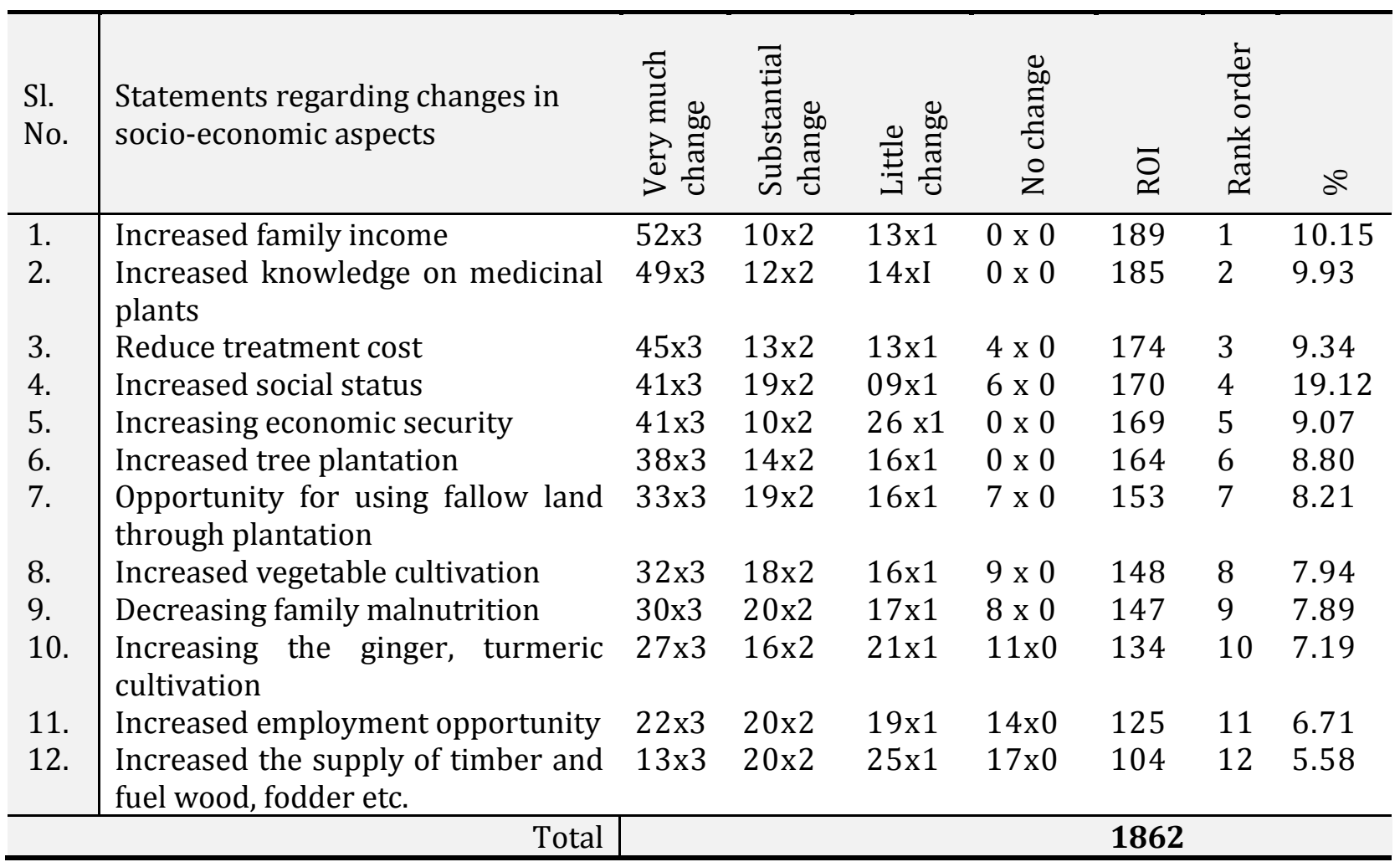

Relationship between the selected characteristics of the respondents with their socio-economic conditions in regards to contribution of medicinal plants: This section deals with the relationship among the 9 selected characteristics of the respondents (independent variables) with their socioeconomic conditions (dependent variable). The characteristics were age, education level, family size, farm size, homestead area, overall annual income, income from medicinal plants, knowledge on medicinal plants and preference towards medicinal plants. Pearson's Product Moment Correlation Coefficient $(r)$ has been used to test the hypothesis concerning the relationship between independent and dependent variables at $0.05(5 \%)$ and $0.01(1 \%)$ level of significance was used as the basis for acceptance or rejection of a hypothesis. The number of possible correlation was calculated between nine independent and one dependent variable. Out of all correlation values six were highly significant, two were statistically non-significant and one was significant which were presented in the Table 05 .

Relationship between age of the respondents with their socio-economic conditions: Relationship between age of the respondents with their socio-economic conditions in regards to contribution of medicinal plants was examined by testing the null hypothesis. "There is no relationship between age of the respondents and their socio-economic conditions". Table 05 indicated that the coefficient of correlation between the concerned variables was found to be $0.211^{\mathrm{NS}}$, which showed that $\mathrm{a}$. The relationship between two variables was positive; $b$. The calculated value of $r=0.211^{\text {NS }}$ also showed insignificant relationship between age of the respondents with their socio-economic conditions. Hence, concerned null hypothesis was accepted. Thus, considering the observed relationship between the concerned variables, researcher concluded that age of the respondents did not influence their socioeconomic conditions in the study area.

Relationship between education level of the respondents with their socio-economic conditions: Relationship between the education level of the respondents with their socioeconomic conditions in regards to contribution of medicinal plants was examined by testing the null hypothesis. "There is no relationship between education of the respondents and their socio-economic conditions". Table 05 indicated that the coefficient of correlation between the concerned variables was found to be $0.487^{* *}$ which showed that a. Relationship between two variables was found positive; b. The calculated value 
of $r=0.487^{* *}$ shows highly significant relationship between two variables at 0.01 level of probability. Hence, concerned null hypothesis was rejected.

Thus, considering the findings, concerned variables implied that more education of the respondents improved their socio-economic conditions substantially. Because educated respondents received much hounour and respect from the society. They were also capable of taking risks to change to alternatives.

\section{Table 05. Correlation between dependent and independent variables}

\begin{tabular}{l|ll}
\hline Dependent variable & Independent variable & Correlation value (r value) \\
\hline & Age & $0.211^{\mathrm{NS}}$ \\
& Education & $0.487^{* *}$ \\
& Family size & $0.354^{* *}$ \\
Socio-economic & Farm size & $0.463^{* *}$ \\
condition & Homestead area & $0.171^{\text {s }}$ \\
& Overall annual income & $0.456^{* *}$ \\
& Income from medicinal plants & $0.550^{*}$ \\
& Knowledge about medicinal plants & $0.470^{* *}$ \\
& Preference towards medicinal plants & $0.542^{* *}$ \\
\hline
\end{tabular}

$*$ Correlation is significant at $5 \%$ level (2-tailed); ${ }^{* *}$ Correlation is significant at $1 \%$ level (2-tailed);NS = Non significant

Relationship between family size of the respondents with their socioeconomic conditions: Relationship between the family size of the respondents with their socio- economic conditions in regards to contribution of medicinal plants was examined by testing the null hypothesis. "There is no relationship between family size of the respondents and their socio-economic conditions". Table 05 indicated that the coefficient of correlation between the concerned variables was found to be $0.354^{* *}$ which lead to the following observations: a. The relationship between two variables was found positive; $b$. The calculated value of $r=0.354^{* *}$ showed highly significant relationship between family size of the respondents with their socio-economic conditions at 0.01 level of probability. Hence, concerned null hypothesis was rejected. Accordingly, in view of the findings, researcher concluded that large families emphasized on the cultivation and conservation of medicinal plants for disease curing and commercial purposes including the kaviraj who had taken these activities as part of his profession that improved their socio-economic conditions.

Relationship between farm size of the respondents with their socioeconomic conditions: Relationship between farm size of the respondents with their socio-economic conditions in regards to contribution of medicinal plants was examined by testing the null hypothesis. "There is no relationship between farm size of the respondents and their socio-economic conditions". Table 05 indicated that the coefficient of correlation between the concerned variables was found to be $0.463^{* *}$ which lead to the following observations: a. The relationship between two variables was found positive; $b$. The calculated value of $r=0.463^{* *}$ showed highly significant relationship between two variables at 0.01 level of probability. Hence, concerned null hypothesis was rejected.

Taking consideration of the findings, researcher observed that socio-economic conditions of the respondents was highly dependent on their farm size as it was farm size was one of the prime factors for getting higher output and annual income of the farm family. As because the land of large farmers were used for many purposes i.e. crop production, vegetable production and tree plantation etc. But, researcher recorded that the number of medicinal plant population were found high in large or medium farms whereas several small and marginal farm family holders were found who willing to cultivate and conserve medicinal plants. But their farm size was too small to raise medicinal plants. For these reasons, statistical analysis of collected data showed highly significant relationship between the farm size of respondents and their socio-economic conditions from the viewpoint of medicinal plant cultivation or conservation.

Relationship between homestead area of the respondents with their socio-economic conditions: Relationship between homestead areas of the respondents with their socio-economic conditions in regards to contribution of medicinal plants was examined by testing the null hypothesis. 
"There is no relationship between homestead area of the respondents and their socio-economic conditions".

Table 05 indicated that the coefficient of correlation between the concerned variables was found to be $0.171^{\mathrm{NS}}$, which lead to the following observations: a. The relationship between two variables was found positive; $b$. The calculated value of $r=0.171^{\text {NS }}$ showed non-significant relationship between homestead area of the respondents with their socio-economic conditions. Hence, concerned null hypothesis was accepted.

So, according to the findings, researcher observed that socio-economic conditions of the respondents were not only depended on their homestead area from the context of medicinal plant species richness. Because a large number of plants were planted in the homestead for various purposes of which a few may or may not possess the medicinal value. Moreover, many peoples were found who had no idea about medicinal plants and consisted almost less or none of that type of plants but owner of a large homestead area. On the other hand, some were found with a small homestead but consisted large number of medicinal plants and had vast knowledge on it. This phenomenon clearly indicated that the homestead area was not at all a major concern and did not bear any effect on the socio-economic conditions of the respondents.

Relationship between overall annual incomes of the respondents with their socio-economic conditions: Relationship between the annual incomes of the respondents with their socioeconomic conditions was examined by testing the null hypothesis. "There is no relationship between annual income of the respondents and their socio-economic conditions". Table 05 indicated that the coefficient of correlation between the concerned variables was found to be $0.456^{* *}$ which lead to the following observations regarding the two variables under consideration: a. The relationship between two variables was found positive; $b$. The calculated value of $r=0.456^{* *}$ showed a highly significant relationship between annual income of the respondents with their socioeconomic conditions at 0.01 level of probability. Hence, concerned null hypothesis was rejected.

Based on the above findings, it may be concluded that higher annual income represents higher socioeconomic conditions of the respondents. A respondent with large annual income receives much hounour and respect from the society. They are capable of taking the risk to change to alternatives and plant many trees for decorating his farm as well as getting special benefits from medicinal plants. They also plant medicinal plant species with agricultural crops under agroforestry system, which ensures production of crops and tree products together, thereby, annual income of the respondents, would go up.

Relationship between income from medicinal plants of the respondents with their socioeconomic conditions: Relationship between income from medicinal plants of the respondents with their socio-economic conditions was examined by testing the null hypothesis. "There is no relationship between income from medicinal plants of the respondents and their socio-economic conditions". Table 05 revealed that the coefficient of correlation between the concerned variables lead to the following observations:

a. The relationship between two variables was found positive; $b$. The calculated value of $r=0.550^{*}$ showed significant relationship between income from medicinal plants of the respondents with their socio-economic conditions at 0.05 level of probability. Hence, concerned null hypothesis was rejected.

Based on the above findings, it may be concluded that majority of the respondents (42\%) who were interviewed (kaviraj) in the study area, gave treatments against different types of diseases by using various medicinal plants and earned extra money from it besides their other income sources. They were also well known and respectable person to the society due to their profession and vast knowledge on medicinal plants. They also reduced their annual expenditure especially for treatment and medication by providing herbal treatments. A minor percent (4\%) of the total respondents earned extra cash from selling bark of Arjun tree, Amloki and the leaves of Ghreetokumari, which had high medicinal value. Therefore, it became very clear that cultivation and conservation of medicinal plants 
always gave extra monetary support to the respondents, which improved their socioeconomic conditions.

Relationship between knowledge on medicinal plants of the respondents with their socioeconomic conditions: Relationship between knowledge on medicinal plants of the respondents with their socio-economic conditions was examined by testing the null hypothesis. "There is no relationship between knowledge on medicinal plants of the respondents and their socio-economic conditions". Table 05 showed that the coefficient of correlation between the concerned variables was found to be $0.470^{* *}$ which lead to the following observations: $a$. The relationship between two variables was found positive; $b$. The calculated value of $r=0.470^{* *}$ showed highly significant relationship between organizational participation of the respondents with their socioeconomic conditions at 0.01 level of probability. Hence, concerned null hypothesis was rejected.

Based on the above findings, it may be concluded that the respondents who had vast knowledge on medicinal plants and their uses attained higher socio-economic conditions in the society and earned extra cash by providing medication to others.

Relationship between preference towards medicinal plants of the respondents with their socioeconomic conditions: Relationship between preference towards medicinal plants of the respondents with their socio-economic conditions in regards to contribution of medicinal plants was examined by testing the null hypothesis. "There is no relationship between preference towards medicinal plants of the respondents and their socio-economic conditions". Table 05 showed that the coefficient of correlation between the concerned variables was found to be $0.542^{* *}$ which lead to the following observations: $a$. The relationship between two variables was found positive; $b$. The calculated value of $r=0.542^{* *}$ showed highly significant relationship between the concerned variables at 0.01 level of probability. Hence, concerned null hypothesis was rejected.

Based on the above findings, it may be concluded that the respondents who had high preference, possessed large number of medicinal plants and those were used for various purposes like treatment of the family members, as vegetables and other commercial uses.

Economic value of medicinal plants: The study revealed that medicinal plants bear a great potentiality from economic point of view. The contribution of medicinal plants in the overall annual income of the respondents was $3.76 \%$ on an average. The other importance of the medicinal plant species was well known. On the basis of economic importance of the medicinal plants, following points were emphasized based on the respondents opinion, which is presented in Table 06. All these things regarding the contribution of medicinal plants finally uplifted the socio-economic conditions of the farmers by improving health, annual income, increased production, reducing household costs etc.

Table 06. Economic importance of the medicinal plants according to the respondents opinion

\begin{tabular}{c|lll}
\hline Sl. No. & Economic importance & Respondents number & $\%$ \\
\hline 1. & Use against diseases of human & 75 & 100 \\
2. & Provide income over time & 58 & 77.33 \\
3. & Aesthetic reasons & 35 & 46.67 \\
4. & Reduce annual cost for treatment & 32 & 42.67 \\
5. & Investment for future & 26 & 34.67 \\
6. & Give food and nutrition & 22 & 29.33 \\
7. & Used as pesticide & 17 & 22.67 \\
8. & Used against livestock diseases & 12 & 16.00 \\
9. & Used as firewood & 9 & 12.00 \\
10. & Supply timber & 7 & 9.33 \\
\hline
\end{tabular}

Reasons of absence of medicinal plant species in the study area

In the study area, there were many reasons behind the absence of medicinal plant species that was conclusively pointed out by the researcher and the major constraints were as follows: 
Table 07. Reasons of absence of medicinal plant species according to the respondents opinion

\begin{tabular}{c|lll}
\hline Sl. No. & Reasons & $\begin{array}{l}\text { Number of } \\
\text { Respondents }\end{array}$ & $\%$ \\
\hline 1. & Jungle clearing for homestead purpose & 48 & 64.00 \\
2. & Jungle clearing for Agricultural uses & 33 & 44.00 \\
3. & Lack of knowledge on production system as well as & 30 & 40.00 \\
& regeneration and management of medicinal plants & & \\
4. & Lack of awareness and familiarity about medicinal plants & 28 & 37.33 \\
5. & (Trees and Shrubs) among peoples & 25 & 33.33 \\
6. & Environmental hazards (flood, drought, excessive rain) & 23 & 30.66 \\
7. & Poverty of the people & 11 & 14.00 \\
8. & Inappropriate agricultural practices & 5 & 6.66 \\
9. & Destruction of village grooves by livestock grazing & 3 & 4.00 \\
10. & Lack of effective supports from GO's and NGO's & 3 & 4.00 \\
\hline
\end{tabular}

The bulk number of medicinal plants is still wild harvested and disappearing rapidly in Bangladesh (FAO, 1984). Only a very small number of species is cultivated.

\section{Impacts of reduction of spread and density of medicinal plants}

The researcher observed that the loss of habitats and over harvesting had threatened the availability of the medicinal plants that are used as the first and last resort for health care by many rural populations during survey. The loss of medicinal plant resources and biodiversity will have direct effects on the lives of poor people, particularly the poor women as they are directly involved with the management of daily household affaires relating to food, family health and nutrition, treatments and income etc. The major impacts of reduction and spread of medicinal species from the study area was erosion of indigenous knowledge of traditional health care system. The other more impacts which also taken in to account were: 1 . Unavailability of the medicinal trees and shrubs when its are needed for taking action against diseases, 2 . Reduce income from medicinal plants and 3. Create extra expenditure due to lack of natural resources

\section{Species conservation}

A total number of 90 useful medicinal species were found in the study area. The present study also revealed that some of the traditional tree and shrub species Horitoki, Bohera, Palash, Raktachandan, Bhuikumri, Anantamul, Shatamul, Ashwagondha, Sharpagondha and Datura etc. were found very rare or not in homestead due to paying less attention. Some farmers reported that they had felled some of the indigenous species replaced by planting exotic species. There is a very little attention regarding strategy and policy has been taken by the Government or non-government institute to preserve the indigenous and minor species from the verge of extinction. Therefore Homestead acts as in-situ conservation of medicinal plant species. Species richness of medicinal plants in the homestead can act as an in-situ germplasm conservation site especially for economically valuable medicinal species.

\section{Conservation aspects}

Most of the respondents (approximately 82\%) pointed out the following steps that should be taken for conservation of some threatened and endangered medicinal plant species in the study area.

\section{Problems regarding cultivation and conservation of medicinal plants}

Different problems and constraints were also noted down during surveyed in the study area. Maximum respondents had given emphasize on lack of time and money, unavailability of the saplings and lack of cultivable lands etc. The associated problems were:

General people are chiefly dependent upon the allopathic treatment, which is proved to be more scientific and less risky. Due to the facts, people seemed to have assembled distrust concerning the treatment based on medicinal plants through kaviraj or traditional village doctors. 
Table 08. Conservation aspects of medicinal plant species according to the respondents opinion

\begin{tabular}{|c|c|c|c|}
\hline Sl. No. & Conservation aspects & $\begin{array}{l}\text { Number of } \\
\text { Respondents }\end{array}$ & $\%$ \\
\hline 1. & Proper management practice should be taken for conservation & 64 & 85.33 \\
\hline 2. & $\begin{array}{l}\text { Awareness should be increased about medicinal plants, their } \\
\text { uses and also economic importance }\end{array}$ & 44 & 8.66 \\
\hline 3. & $\begin{array}{l}\text { Collection and plantation of economically potential medicinal } \\
\text { plants should be increased }\end{array}$ & 32 & 42.66 \\
\hline 4. & Deforestation need to be discouraged & 21 & 28.00 \\
\hline 5. & $\begin{array}{l}\text { Protection measures should be taken to conserve medicinal } \\
\text { plant species }\end{array}$ & 19 & 2.33 \\
\hline 6. & Medicinal plants should be grown in highland & 14 & 18.67 \\
\hline 7. & $\begin{array}{l}\text { Training facilities should be provided for collection and } \\
\text { conservation of medicinal plants }\end{array}$ & 11 & 9.33 \\
\hline 8. & Cultivated area of medicinal plants need to be increased & 5 & 6.67 \\
\hline 9. & Medicinal plant nursery need to be increased & 3 & 4.00 \\
\hline
\end{tabular}

Table 09. Problems regarding cultivation and conservation of medicinal plants according to the respondents opinion

\begin{tabular}{|c|c|c|c|}
\hline Sl. No. & Problems & $\begin{array}{l}\text { Number of } \\
\text { respondents }\end{array}$ & $\%$ \\
\hline 1. & $\begin{array}{l}\text { Most of the lands of respondents' in the study area were used for } \\
\text { cultivation of major crops like rice, jute, wheat etc. The homestead } \\
\text { areas were utilized for cultivation of seasonal vegetables and } \\
\text { plantation of different fruits and timber species }\end{array}$ & 51 & 68.00 \\
\hline 2. & $\begin{array}{l}\text { Lack of money and time for cultivation and conservation of } \\
\text { medicinal plants }\end{array}$ & 48 & 64.00 \\
\hline 3. & $\begin{array}{l}\text { Lack of facilities for procuring seed or sapling of medicinal plants } \\
\text { according to their demand due to unavailability }\end{array}$ & 44 & 58.66 \\
\hline 4. & $\begin{array}{l}\text { Lack of necessary inputs for cultivation of medicinal plant species } \\
\text { such as seed, seedling, fertilizer, water, pesticides, insecticides etc. }\end{array}$ & 28 & 37.33 \\
\hline 5. & $\begin{array}{l}\text { Maximum medicinal species specially shrubs are affected and } \\
\text { destroyed due to excessive rain causing floods, seasonal storms, } \\
\text { land slide and drought }\end{array}$ & 23 & 30.66 \\
\hline 6. & $\begin{array}{l}\text { Due to poverty of the rural people they cannot invest extra money } \\
\text { for medicinal plant cultivation }\end{array}$ & 19 & 25.33 \\
\hline 7. & $\begin{array}{l}\text { Lack of monetary and technical support through credit or training } \\
\text { from GOs and NGOs }\end{array}$ & 18 & 24.00 \\
\hline 8. & Lack of willingness for cultivation of medicinal plants & 16 & 21.33 \\
\hline 9. & $\begin{array}{l}\text { Lack of highland, which is suitable for cultivation and } \\
\text { conservation of medicinal plants }\end{array}$ & 13 & 17.33 \\
\hline 10. & Lack of awareness about the importance of medicinal plants & 12 & 16.00 \\
\hline 11. & Lack of medicinal plant nurseries & 8 & 10.66 \\
\hline 12. & $\begin{array}{l}\text { Lack of scientific knowledge on the production system of } \\
\text { medicinal plants }\end{array}$ & 3 & 4.00 \\
\hline
\end{tabular}

\section{Conclusion}

The findings implied that contribution of medicinal plants in the overall annual income of the respondents was $3.76 \%$ on an average. Many peoples were found in the study area that had been practicing the traditional health care systems for years. The findings indicated that the respondents, who used various medicinal plants against different diseases, saved money and earned extra cash through selling the indigenous plant products. It was noticed that $4 \%$ of the total respondents in the study area earned extra cash from selling bark of Arjun tree, Amloki and the leaves of Ghritokumari, which had a lofty medicinal value. Consequently, it became very clear that cultivation and conservation of medicinal plants always gave extra monetary support to the respondents, which 
improved their socio-economic conditions. Although growing medicinal plants and benefits from them have been appeared as a potential enterprise to the concerned households, but several problems such as scarcity of land, money inputs etc. were found to be potential barriers for their commercial cultivation and utilization.

\section{References}

[1]. BARC (Bangladesh Agriculture Research Council). (1972-1992). Flora of Bangladesh. Salar, M. K. (ed.) BARC, Dhaka

[2]. Bashar, M. A. (1999). Home Garden Agroforestry: Impact on Biodiversity Conservation and Household Food Security. A case study of Gazipur district, Bangladesh. M. S. thesis, Dept. of Mgt. Natural Resources and Sustainable Agric., Agril. Univ. Nov. p 42.

[3]. Bashu, S. K. and Manna, M. K. (1997). Conservation of Some Wetland Species of Socio-economic Importance with reference to West Bengal, India. Program and Abstract. 9t' Biennial Botanical Conference. Bangladesh Botanical Society, 8-9 January 1997. University of Dhaka, Dhaka.

[4]. Chevallier, A. (1996). The Encyclopedia of Medicinal Plants. First edition. DK Publishing Inc., New York.

[5]. Chopra, R. N., Nayar, S. L. and Chopra, I. C. (1992). Glossary of Indian Medicinal Plants. CSIR, New Delhi.

[6]. Das, K. D. and Alam, M. K. (2001). Trees of Bangladesh. Bangladesh Forest Research Institute, Chittagong.

[7]. Hannah, L. and Bowles, I. (1995). Letters, global properties. Bioscience. pp. 45-122. https://doi.org/10.2307/1312547

[8]. Rahman, M. (2003). Science World: Veshog Udvider Rokomfer (in Bangla). Proffessor's Prokashon, Dhaka. June 2003, p. 46.

[9]. Rashid, M. H., Alam, M. J., Ara, R. and Merry, S. R. (1987). Crude Drug Market Survey, Bangladesh. Bangladesh Forest Research Institute, Chittagong (Unpublished).

[10]. Roy, P. (2001). The Daily Bhorer Kagaz: Bangladesher Biponno Jeeb Boichitro 6 (in Bangla). December, pp. 1-2.

[11]. Silva, T. D. (1997). Industrial Utilization of Medicinal Plants in Developing Countries. Nonwood forest products-11, Medicinal plants for forest conservation and health care, FA0, Rome, Italy, p.34.

[12]. Walden, I. (1995). Preserving Biodiversity: The role of property rights. In: Swanson, T. Ed. Intellectual Property Rights and Biodiversity Conservation: An Interdisciplinary Analysis of the Values of Medicinal Plants. Cambridge University Press, UK. 176-198. https://doi.org/10.1017/CB09780511623417.009

[13]. Xiao, Pei-Gen. (1991). The Chinese Approach to medicinal Plants. In: Akerele, O., V. Heywood and H. Synge (Eds). Conservation of Medicinal Plants. Cambridge University Press, UK. 305313. 